\title{
Diálogo da misericórdia: estudo sobre um tema da Bula Misericordiae Vultus
}

\author{
Dialogue of Mercy: \\ Study of a theme from the Bull \\ Misericordiae Vultus
}

Maria Teresa de Freitas Cardoso

\section{Resumo}

Este artigo elabora uma síntese da Misericordiae Vultus, do Papa Francisco, e considera especialmente o $\mathrm{n}$. 23, em vista de um diálogo mais amplo sobre a misericórdia. Mostra a atualidade e importância do tema. Para os cristãos, o tema da misericórdia é central na sua fé em Deus e na práxis do seguimento de Cristo. $\mathrm{O}$ artigo levanta elementos significativos e representativos para um diálogo da misericórdia entre os cristãos, com os Judeus e com outras tradições religiosas. O tema interessa a um diálogo com todas as pessoas e também na interdisciplinaridade. $\mathrm{O}$ artigo conclui que o diálogo da misericórdia e da compaixão mereceria ser sempre aprofundado.

Palavras-chave: Misericórdia. Compaixão. Fé. Vida cristã. Diálogo.

\section{Abstract}

This article elaborates a synthesis of Misericordiae Vultus, of Pope Francis, and it considers specially no. 23, in view of a broader dialogue about mercy. It shows the relevance and importance of the theme. For Christians, the theme is central in its faith in God and in the praxis of following Christ. This article raises significant and representative elements for a dialogue of mercy 
among Christians, with the Jews and with other religious traditions. The theme is important to a dialogue with all persons and also for interdisciplinarity. The article concludes that the dialogue of mercy and of compassion deserves to be continually deepened.

Keywords: Mercy. Compassion. Faith. Christian life. Dialogue.

\section{Introdução}

Este artigo contempla um tema da bula Misericordiae Vultus (MV), de proclamação do Jubileu Extraordinário da Misericórdia (dado em 2015 a 2016). Ali o Papa propõe aos fiéis católicos fundamentos da fé e diretrizes para viver na misericórdia. Ali, o incentivo a um diálogo mais amplo, inclusive no âmbito inter-religioso.

O motivo deste estudo é que o tema da misericórdia hoje precisa ser contemplado e compartilhado, com vistas a um seu aprofundamento na reflexão e na vida. Considera-se que a misericórdia é dom do amor de Deus e tema profundamente religioso e humano. Junto com a misericórdia, poderiam ser considerados também atitudes como empatia, solidariedade e compaixão. $\mathrm{O}$ tema envolve a fé em Deus e a prática concreta.

$\mathrm{O}$ artigo propõe os seguintes passos: considerar a importância e a atualidade do tema da misericórdia; fazer uma síntese da bula Misericordiae Vultus; e entrever elementos significativos para um diálogo da misericórdia e da compaixão - entre cristãos, no diálogo com os Judeus e com outras grandes tradições religiosas. As aproximações que faremos, que não pretendem ser completas, visam a representar a importância do diálogo. Um diálogo da misericórdia torna-se importante e merece ser mais e mais desenvolvido.

Ao buscarmos aproximações de interesse ecumênico e inter-religioso, a intenção não é reduzir a um denominador comum, mas ver pontos de contato e contribuições, que, a partir de perspectivas diversas, podem se comunicar e inspirar aprofundamentos do tema. $\mathrm{Na}$ fé cristã, o tema tem raízes na revelação de Deus no seu amor com implicações para a práxis da fé. Porém, é um tema com uma valência maior, com contribuições inter-religiosas. Além disso, seria interessante ver contribuições da filosofia e das diferentes disciplinas humanas, pois haveriam de enriquecer a reflexão com seus próprios aprofundamentos e sugestões. A misericórdia torna-se um tema grande e atual para um diálogo amplo e uma busca de atuação em favor do ser humano. 


\section{Importância e atualidade de um diálogo da misericórdia}

Já um pouco antes do Jubileu Extraordinário da Misericórdia, Walter Kasper propunha uma importante obra sobre a misericórdia, ${ }^{1}$ na qual ele chamava a atenção para a centralidade do tema na fé e na vida cristã. Ele observava que, apesar de ser um tema bíblico tão importante, parecia esquecido na teologia sistemática. Por isso, Walter Kasper dedicou-se a escrever um livro sobre esse tema, que tem servido de inspiração para muitas reflexões e mesmo para a proclamação do Jubileu Extraordinário da Misericórdia. Walter Kasper mostrava como a questão da misericórdia é importante e atual. Ele levantou indicações da filosofia e das religiões, fazendo ver que o tema está no âmago da inquietação humana. Destacou principalmente dados bíblicos e sistemáticos, pelos quais se depreende que a misericórdia é central na revelação e constitui o atributo mais importante de Deus. O autor considerou a práxis cristã e eclesial. Trata-se de um estudo denso e significativo, cuja leitura foi apreciada pelo próprio Papa Francisco, que a recomendou. Neste artigo em alguns momentos retomaremos suas indicações.

O Jubileu tornou-se uma ocasião de aprofundamento da misericórdia. Nosso propósito é refletir a partir dos dados principais da Bula MV. Vários estudos desenvolveram-se sobre o tema do Jubileu, sem podermos aqui retratá-los. Porém, não se trata só do evento do Jubileu. É que o tema é importante e urgente não só para os cristãos, mas para toda a humanidade. Como Kasper considerou no seu estudo, especialmente referindo-se aos sofrimentos do século XX e do século XXI, existe um clamor nos nossos tempos. São muitas as inquietações. As condições de vida são muitas vezes desumanas. Clamam por misericórdia. Misericórdia é o caminho necessário, pois, como disse Leonardo Agostini, "miséria é tudo o que é desumano e misericórdia é tudo o que humaniza".2

Manuel Sánchez Monge salienta que com a misericórdia se trata de uma modalidade de amor, da força do amor, de seu compromisso, de sua expressão e suas obras: "A misericórdia não é um sentimento superficial, uma comoção romântica que logo passa [...] A misericórdia não é fraqueza, mas a fortaleza

\footnotetext{
${ }^{1}$ Referimo-nos à obra de KASPER, W. A misericórdia: condição fundamental do Evangelho e chave da vida cristã. São Paulo: Loyola 2015.

${ }^{2}$ AGOSTINI, L. Eterna é a sua misericórdia: Reflexões bíblicas e Leituras orantes. São Paulo: Paulinas, 2016, p. 13. Vejam-se no livro o estudo de várias referências do tema na Bíblia, com meditações e sugestões.
} 
daquele que ama.[...] É o amor que se encontra com a miséria do outro a quem ama". ${ }^{3}$

Ele mostra que "o mundo de hoje carece de coração e perdeu a capacidade de compaixão. Sobra-lhe comunicação, porém falta-lhe misericórdia. Falta-lhe proximidade cordial aos outros para curar suas feridas. Seguramente, o mal de nosso tempo está em viver sem coração". ${ }^{4}$ Entretanto, atitudes de misericórdia, empatia e compaixão são recomendadas hoje mesmo em vários âmbitos profissionais:

Ainda que alguns pensem que os termos 'compaixão'e 'misericórdia'não estejam em moda, não ocorre o mesmo com as atitudes e condutas que denotam. A 'empatia', isto é, compreender alguém tratando de identificar-se afetivamente com ele, tratar de colocar-se em seu lugar para compreender sua maneira de pensar e atuar, vem recomendada pela psicologia, pela psicoterapia, pela pedagogia, pela sociologia e pela pastoral modernas". ${ }^{5}$

Depois de aprofundar a fé cristã e a prática da misericórdia, Sánchez Monge desdobra vários âmbitos nos quais praticar a misericórdia: o perdão e a reconciliação na convivência social; o espírito do amor na família; a necessidade das obras de misericórdia, como no auxílio aos pobres e excluídos, para com os que estão enfermos ou sofrem de algum modo. Acrescenta-se ainda a vida pública. Enfim, para Sánchez Monge, estamos às voltas com "um desafio cultural". ${ }^{6}$ É um tema a aprofundar em nosso tempo. A discussão tenha em conta como a misericórdia tem sido enfatizada pelo Papa Francisco, e mais ainda com o Jubileu.

Porém, o amor, a misericórdia, a compaixão, a benevolência... ultrapassam as fronteiras visíveis do cristianismo. Walter Kasper em suas obras sobre a misericórdia recorda a regra de ouro nas religiões:

Em quase todas as religiões da humanidade aparece a chamada regra de ouro: Não faças a outrem o que não queres que te façam a ti'; ou, em formulação positiva: Faze aos outros o que desejarias que te fizessem a ti'. Esta regra de ouro é uma herança de toda a humanidade. Trata-se de uma

\footnotetext{
${ }^{3}$ SÁNCHEZ MONGE, M. Este es el tiempo de la misericordia. Maliaño: Sal Terrae, 2016, pp. 19-20.

${ }^{4}$ Ibidem, p. 13.

${ }^{5}$ Ibidem, p. 19.

${ }^{6}$ Ibidem, p. 165.
} 
regra de empatia que exige ir além do próprio eu, de colocar-se na situação do outro e de atuar como eu desejaria que o outro atuasse comigo em tais situações". Esses exemplos mostram uma concepção do ser humano que não é auto-referencial nem está encerrado em si mesmo, mas que é uma pessoa que deve abrir-se ao outro; uma antropologia do empáthein e do simpáthein com o outro, e uma compreensão de si mesmo a partir do outro, com relação ao outro e no outro. ${ }^{7}$

É verdade que as religiões e as filosofias não se apresentam com a mesma perspectiva nas suas considerações sobre o ser humano, as relações com os outros, o universo e Deus. Porém, uma abertura ao diálogo respeita perspectivas e acolhe contribuições, valores espirituais e humanos, inclusive porque podem contribuir na dignificação do ser humano e no caminho da libertação.

\section{O conteúdo da Bula Misericordiae Vultus e a busca de um diálogo maior}

As primeiras palavras da Bula Misericordiae Vultus,${ }^{8}$ para a proclamação do Jubileu Extraordinário da Misericórdia, dando o nome ao documento, descrevem Jesus Cristo como "o rosto da misericórdia do Pai" (MV, n. 1). O papa Francisco queria sugerir a síntese do mistério da fé cristã. Ele começa o desenvolvimento da reflexão por destacar que Deus se revelou a Moisés como "Deus misericordioso e clemente, lento na ira, cheio de bondade e fidelidade" (Ex 34, 6). Acrescenta que "na plenitude do tempo" Deus revelou-se em Cristo. E Cristo "revela a misericórdia de Deus" (MV, n. 1).

O papa observa que "precisamos sempre contemplar o mistério da misericórdia", que "é fonte de alegria, serenidade e paz" e "condição de nossa salvação" (MV, n. 2). Deus vem ao nosso encontro com misericórdia e a misericórdia é a "a lei fundamental que mora no coração de cada pessoa quando vê com olhos sinceros o irmão" (n. 2).

O papa faz ver que há momentos em que é preciso "fixar o olhar na misericórdia", de modo que proclama "um Jubileu Extraordinário da Misericórdia como tempo favorável para a Igreja", para nos tornarmos mais um "sinal eficaz do agir do Pai" (MV, n. 3). Para que se abra uma "Porta da Misericórdia"

\footnotetext{
${ }^{7}$ KASPER, W. El desafio de la Misericordia. Maliaño: Sal Terrae, 2015, p. 30.

${ }^{8}$ FRANCISCO, PP. Misericordiae Vultus. Bula de proclamação do Jubileu Extraordinário da Misericórdia. São Paulo: Paulinas, 2015.
} 
para todos, "onde qualquer pessoa que entre poderá experimentar o amor de Deus que consola, perdoa e dá esperança" (MV, n. 3). O Ano Santo comemora os cinquenta anos de encerramento do Concílio, no qual a Igreja quis usar a linguagem da caridade, da misericórdia. Quis honrar os valores humanos e servir aos seres humanos (MV, n. 4). O Ano Santo termina com gratidão, confiando a Igreja, a humanidade e o universo à Realeza de Cristo, no desejo de um futuro com os sinais do Reino entre nós: sinais da misericórdia, da bondade e da ternura de Deus (MV, n. 5).

O Papa cita São Tomás de Aquino, que ensinou que "é próprio de Deus usar de misericórdia" e que nisso "se manifesta de modo especial a sua onipotência". Com misericórdia, Deus revela-se presente, "aquele que é próximo, providente, santo e misericordioso" (MV, n. 6).

A revelação da misericórdia de Deus é largamente contemplada no Antigo Testamento. Os Salmos proclamam que Deus perdoa a culpa, cura as enfermidades, resgata a vida, enche de graça e ternura (S1 103). E que Deus liberta, levanta, ama (S1 146; 147). Assim o amor de Deus é um amor "visceral". Deus manifesta um amor de "ternura e compaixão, de indulgência e perdão" (MV, n. 6). Um salmo, o grande Hallel, cantado em grandes festas, proclama, como refrão, que "Eterna é a sua misericórdia" (S1 136) e relembra a história da salvação. O papa faz ver que Jesus rezou esse salmo de misericórdia antes da paixão e que abraçou essa misericórdia. O papa acrescenta que isso implicaria em assumirmos o mesmo refrão em nossa oração (MV, n. 7).

O Novo Testamento também anuncia a misericórdia e mostra Jesus compassivo, curando, acolhendo, saciando com pães, perdoando os pecadores. $\mathrm{O}$ papa destaca o episódio em que Jesus olha Mateus com misericórdia e o escolhe para apóstolo. O episódio é comentado por Beda o Venerável. Torna-se o lema do próprio papa: "miserando atque eligendo" (MV, n. 8).

Lugar especial se dá às parábolas da misericórdia, ensinadas por Jesus: da ovelha extraviada, da moeda perdida, do pai com seus dois filhos (Lc 15, 1-32). Chama a atenção para a alegria do Pai que perdoa e consola. As parábolas revelam o Pai misericordioso. Jesus ensina que somos chamados por nossa vez a perdoar, perdoar sempre. Conta a parábola do senhor que admoestou o servo perdoado, que devia por sua vez perdoar o companheiro (Mt 18). Finalmente, lembra a bem-aventurança dos misericordiosos: bem-aventurados os misericordiosos - a inspirar-nos no Ano Santo, pois "somos chamados também nós a ser misericordiosos uns para com os outros" (MV, n. 9).

O ponto seguinte é que a Igreja deve ter o desejo inexaurível de oferecer 
misericórdia. Com ternura, falar aos crentes. Exercer toda a missão com amor misericordioso e compassivo. Anuncia o perdão ( $\mathrm{MV}, \mathrm{n}$. 10), que, como ensinara João Paulo II, não deve cair no esquecimento (MV, n. 11). Ao mesmo tempo que anuncia a misericórdia, deve a Igreja viver e testemunhar ela mesma a misericórdia (MV, n. 12), pois, para a Igreja, a primeira verdade é o amor de Cristo e ela deve ser serva e mediadora do amor de Cristo. Assim, onde houver Igreja, onde houver cristãos, deve haver misericórdia (MV, n. 12).

O lema do Ano Jubilar foi a palavra do Senhor: "misericordiosos como o Pai" (inspirado em Lc 6, 36). É preciso escutar a Palavra, meditá-la, assumi-la como estilo de vida (MV, n. 13). As peregrinações do Ano Santo seriam sinal de uma caminhada para a misericórdia, seja para os fiéis deixarem-se alcançar pela misericórdia de Deus, seja para comprometerem-se em ser misericordiosos (MV, n. 14). Isso implica em não julgar nem condenar. Em perdoar e em doar-se. A partir da experiência da presença e proximidade de Deus, tornar-se compassivo para com todos (MV, n. 14).

O papa considera "quantas situações de precariedade e sofrimento presentes no mundo atual!" (MV, n. 15). Daí a necessidade de obras de misericórdia. E os cristãos devem praticar obras de misericórdia. A Igreja é chamada a cuidar dos que sofrem. As obras de misericórdia são diversas. Algumas se enunciam como obras de misericórdia corporal e outras se enunciam como obras de misericórdia espiritual.

Entre as obras de misericórdia corporal, devemos: dar de comer aos famintos; dar de beber aos sedentos; vestir os nus; acolher os peregrinos; dar assistência aos enfermos; visitar os presos; enterrar os mortos. Entre as obras de misericórdia espiritual devemos: aconselhar os indecisos; ensinar os ignorantes; admoestar os pecadores; consolar os aflitos; perdoar as ofensas; suportar com paciência as pessoas molestas; rezar pelos vivos e defuntos.

Tais obras, de misericórdia corporal e espiritual, são expressão de amor. Além da alusão da MV ao texto sobre o Juízo em que Jesus se apresenta como aquele a quem fizemos ou não fizemos as obras de misericórdia (Mt 25), observamos aqui que a ideia de que precisamos de amor e que devemos realizar obras de amor se ilustra com uma citação feita pelo papa sobre uma bela expressão de S. João da Cruz, afirmando que, "ao entardecer desta vida, examinar-nos-ão no amor" (MV, n. 15).

As obras de misericórdia correspondem às obras de Cristo, que, segundo Lc 4 citando Isaías, anuncia a boa nova, consola, cura e liberta, com o ano da graça. Os cristãos são chamados a exercerem a misericórdia com alegria (MV, 
n. 16). A quaresma, que é tempo especial de oração, jejum e caridade, deve ser tempo propício para se experimentar o perdão e a reconciliação. É tempo para o primado da misericórdia ( $\mathrm{MV}, \mathrm{n}$. 17). O papa convida os fiéis a aproximarem-se da misericórdia (MV, n. 18) e convida à conversão todos que possam estar afastados da graça (MV, n. 19).

A MV aproxima justiça e misericórdia. Recorda o texto de Mateus: "Ide aprender o que significa: Prefiro a misericórdia ao sacrifício". Isso estaria na linha do que foi proposto por Oséias: "Eu quero a misericórdia e não os sacrifícios". Outros textos, do NT e do AT, aproximam a justiça de Deus e o "o seu perdão" (MV, n. 20). Ainda citando Oseias, recorda-se que Deus no seu amor se comove. Ele não contém a sua misericórdia (MV, n. 21). A misericórdia, que supõe a justiça, engloba-a e supera-a. É que "esta justiça de Deus é a misericórdia concedida a todos como graça, em virtude da morte e ressurreição de Jesus Cristo" (MV, n. 21). Desse modo, com ela Deus mostra perdão e indulgência. (MV, n. 22).

Depois dessas reflexões, o papa considera que "a misericórdia tem uma valência que ultrapassa as fronteiras da Igreja” (MV, n. 23). Daí uma proposta de diálogo aberto ao âmbito inter-religioso: o ano jubilar deve ser "vivido na misericórdia", "favorecer o encontro com as religiões", tornar-nos "abertos ao diálogo". Deve eliminar fechamentos, desprezos, violências, discriminações, e sim implicar em uma convivência de respeito e de paz (MV, n. 23).

No final, a MV contempla Maria, a Mãe da Misericórdia, a quem os fiéis hão de pedir volva para nós o olhar misericordioso (MV, n. 24). A bula se encerra com o dado de que a Igreja "é chamada em primeiro lugar a ser verdadeira testemunha da misericórdia, professando-a e vivendo-a como o centro da Revelação de Jesus Cristo", porque tem presente que "do coração da Trindade [...] brota [...] a grande torrente da misericórdia" (MV, n. 25).

Portanto, todo o documento enfatiza a importância da misericórdia e sua centralidade na fé e na prática cristã, merecendo por isso ser tema de diálogo dos cristãos. Além disso, verificamos na referência ao parágrafo de n. 23, a sua apreciação como valor para um diálogo mais amplo e como uma base de boas práticas na convivência, abertura, estima, respeito e paz.

Dentro da busca de um diálogo maior, em um círculo mais universal, se nos colocarmos de acordo com as inspirações da encíclica Ecclesiam Suam, de Paulo VI, quando promovia o espírito dos diálogos desejados pelo Concílio Vaticano II, veremos que não se trata de impingir crenças, ainda que estas devam ser anunciadas e testemunhadas, mas trata-se sobretudo de favorecer uma 
maior comunhão, porque a relação do diálogo, dizia Paulo VI, "se é certo que não visa a obter sem demoras a conversão do interlocutor, porque lhe respeita a dignidade e liberdade, sempre visa ao bem dele e procura dispô-lo à comunhão mais plena de sentimentos e convicções" (ES, n. 46). ${ }^{9}$

Haveríamos então de pensar na dimensão ecumênica como uma abertura a favorecer maior comunhão entre as pessoas. Esse diálogo de maior comunhão e de procura do bem de todos abraça o que é humano. Na mesma encíclica que acabamos de citar, Paulo VI falava em diversos círculos de diálogo, começando por abrir-se para a humanidade toda, a ter presente que "tudo o que é humano nos diz respeito" (ES, n. 54). Essa abertura a tudo o que é humano e busca de tudo o que humaniza haveria de encontrar caminho próprio na misericórdia. Esse é um campo para um diálogo verdadeiramente amplo, que aqui quereríamos valorizar.

Apresentaremos a seguir elementos de aproximações diversas do âmbito ecumênico e inter-religioso, como uma representação de riquezas de um diálogo que pode ser bem maior.

\section{No diálogo dos Cristãos}

A misericórdia deve ser aprofundada já na Igreja, com o diálogo ecumênico dos cristãos. É expressiva a riqueza da MV com várias referências bíblicas e da tradição espiritual da Igreja, para iluminar o diálogo dos cristãos sobre a misericórdia e animar uma vida na misericórdia.

Os cristãos podem apoiar-se uns aos outros na busca do Deus misericordioso e no acolhimento de sua graça, que é preciosa e que compromete. Contemplarão juntos Jesus como o rosto da misericórdia do Pai. Aprofundarão as riquezas da misericórdia de Deus. Estarão juntos na invocação do Espírito e na edificação uns dos outros pelos dons do Espírito, com o primado da caridade. Compartilharão a oração do Pai-Nosso, que pede a Deus o perdão abrindo o próprio coração a perdoar. A missão dos cristãos no mundo levará a proclamar, por meio de palavras e obras, as misericórdias de Deus. A MV é para os cristãos uma síntese oportuna de dados da fé em Deus misericordioso e da vida de filhos misericordiosos como o Pai, que vivem esse espírito na oração e na ação.

Para os cristãos, não só os católicos, o momento é de aprofundar o tema

${ }_{9}^{9}$ PAULO VI. Encíclica Ecclesiam Suam. In: Documentos de Paulo VI. São Paulo: Paulus, 1997. 
da misericórdia. Especialmente, porque esta é uma necessidade especial dos nossos tempos. O Jubileu tornou-se uma ocasião de diálogo dos cristãos, mas o diálogo não se restringe ao tempo do Ano Jubilar. A comemoração dos 500 anos da Reforma torna-se por sua vez uma ocasião propícia para o diálogo e depois dessa comemoração o diálogo deverá ainda ser aprofundado. Deve ser um diálogo de irmãos. Deve-se levar adiante um diálogo da misericórdia de Deus, diálogo da caridade, diálogo do perdão e da reconciliação, do serviço da misericórdia no mundo, como missão.

A ocasião das comemorações de 500 anos de Reforma é oportuna para acentuar no diálogo a contribuição de Lutero ao enfatizar a pergunta pelo Deus misericordioso. É sabido que Lutero se perguntou: "Onde encontro eu um Deus misericordioso?". A partir daí desenvolve-se toda uma reflexão sobre a justiça divina, justiça justificadora, a misericórdia. Walter Kasper mostra que entre luteranos e católicos "até o século XX não se conseguiu chegar a um acordo fundamental" sobre a justificação, mas que no final do século "isso só foi possível porque juntos reconhecemos que a justiça de Deus é a sua misericórdia". ${ }^{10}$ Kasper pondera ainda que Martinho Lutero tem hoje uma especial importância ecumênica e sublinha que a maior contribuição ecumênica de Lutero está na questão da misericórdia:

A mais importante contribuição de Martinho Lutero para o avanço do ecumenismo não se enraíza nas aproximações eclesiológicas, nele contudo abertas, mas em sua originária concentração - como ponto de partida - no evangelho da graça e da misericórdia de Deus e no chamado à conversão. A mensagem sobre a misericórdia divina era a resposta tanto a suas interrogações e necessidades pessoais como às perguntas da época; e também hoje constitui a resposta aos sinais dos tempos e às perguntas prementes de muitas pessoas. Somente a misericórdia divina pode estancar as profundas feridas que a separação infligiu ao corpo de Cristo, que é a Igreja. ${ }^{11}$

Na interpretação de Lucien Febvre, no caminho da reforma Lutero procurou passar às pessoas, o "quanto podia, o mais que podia, desse sentimento patético [...], dessa impetuosidade [...] com que experimentava, no fundo de sua consciência, a santidade absoluta de Deus, a ilimitada onipotência de sua

\footnotetext{
${ }^{10}$ KASPER, W. A misericórdia: condição fundamental do Evangelho e chave da vida cristã, p. 26.

${ }^{11}$ KASPER, W. Martín Lutero - Una perspectiva ecuménica. Maliaño: Sal Terrae, 2016, p. 73.
} 
vontade, a desmedida liberdade de Sua misericórdia. Exatamente por isso, via-se trabalhando em uma reforma religiosa empreendida por dentro, e não por fora". ${ }^{12}$

Também os católicos devem a cada dia procurar seu encontro pessoal e comunitário com o Deus misericordioso e deixar-se tocar pela graça de Deus. Eles poderiam de certo modo refazer a interrogação de Lutero que clama pelo Deus misericordioso e vê a resposta na graça preciosa. A abertura à misericórdia e à graça de Deus são elementos comuns, que podem ser aprofundados entre os católicos e cabem na sua busca de renovação, posto que o Concílio Vaticano II fez ver que a Igreja precisará sempre de uma reforma perene. ${ }^{13}$

Uma reflexão luterana que faz refletir sobre o amor misericordioso encontramos no teólogo luterano Dietrich Bonhoeffer, a propósito das bem-aventuranças na obra sobre o discipulado. Suas palavras foram citadas por Walter Kasper no seu estudo sobre a misericórdia. Bonhoeffer coloca diante dos olhos traços de compaixão, solidariedade e amor pelos desvalidos, de acordo com o próprio exemplo de Cristo. É que a kénosis de Cristo manifesta sua misericórdia. Citaremos um trecho da reflexão de Bonhoeffer citada por Kasper, mas transcreveremos a citação diretamente a partir da edição brasileira do livro de Bonhoeffer:

Esses desapropriados, estranhos, impotentes, pecadores, esses seguidores de Jesus vivem, em sua companhia, também na renúncia à dignidade própria, pois são misericordiosos. Não se satisfazem com a própria miséria e carência, mas ainda compartilham a miséria, humilhação e culpa alheias. Sentem amor irreprimível pelos humildes, enfermos, miseráveis, oprimidos e violados, injustiçados e marginalizados, por todos os magoados e angustiados; buscam os que caíram em pecado e culpa. Por maior que seja a miséria, por mais horrível que seja o pecado, a misericórdia os visita. O misericordioso empresta a honra própria ao decaído e toma sobre si sua vergonha. [...] Conhecem uma única dignidade e honra: a misericórdia do Senhor em função da qual vivem exclusivamente. Ele não se envergonhou dos discípulos, ele se fez irmão dos seres humanos [...] Essa é a misericórdia de Jesus da qual querem viver os que a ela estão ligados, a misericórdia do Crucificado [...] Bem-aventurados os misericordiosos, porque têm por Senhor o Misericordioso. ${ }^{14}$

\footnotetext{
${ }^{12}$ FEBVRE, L. Martinho Lutero, um destino. São Paulo: Três Estrelas, 2012, pp. 143-144.

${ }^{13}$ CONCÍLIO VATICANO II. Decreto Unitatis Redintegratio, sobre o ecumenismo, n. 6.

${ }^{14}$ BONHOEFFER, D. Discipulado. São Leopoldo: Sinodal, 2004, p. 63.
} 
No final do seu livro supracitado, Bonhoeffer tem em conta que os discípulos são feitos imagem de Cristo e que "o Encarnado faz de seus discípulos irmãos de todos os seres humanos", posto que "a 'filantropia'de Deus (Tt 3,4) revelada na encarnação de Cristo é a base do amor fraternal dos cristãos para com todos os seres humanos sobre a terra". Assim, com suas boas obras, vivendo a vida de Cristo, o discípulo será "portador da imagem do Cristo encarnado, crucificado e ressurreto". ${ }^{15}$ Essas colocações inspirariam um diálogo da misericórdia entre os cristãos, o que se enriqueceria com a contemplação dos próprios mistérios de Cristo.

\section{No diálogo com os Judeus}

O papa Francisco no final da MV fez ver que as suas explanações sobre a misericórdia percorreram várias páginas do Antigo Testamento. Lá podemos contemplar a revelação histórica da misericórdia de Deus, manifestada a seu povo, sendo que o Papa diz que Israel recebeu essa revelação como por primeiro, porém tratando-se de uma riqueza para a humanidade inteira. Importa frisar aqui a observação de que o AT está permeado da misericórdia, com muitas indicações que significam esse amor universal de Deus:

Israel foi o primeiro que recebeu esta revelação, permanecendo esta na história como o início de uma riqueza incomensurável para oferecer à humanidade inteira. Como vimos, as páginas do Antigo Testamento estão permeadas de misericórdia, porque narram as obras que o Senhor realizou em favor do seu povo, nos momentos mais difíceis da sua história. (MV, n. 23)

A misericórdia é revelada no Antigo Testamento ou Primeiro Testamento. São tantos os elementos que a MV levanta e que podem ser retomados no diálogo com os Judeus. Os principais foram indicados na visão sintética que fizemos sobre a MV. Em especial, teríamos: a revelação de Deus a Moisés, como "Deus misericordioso e clemente [...] de bondade e fidelidade" (Ex 34, 6), tema que está no início da MV. Mas temos também a história do povo; o testemunho dos Salmos; as exigências dos profetas. Tantas páginas bíblicas poderiam ser lembradas.

Entre os livros sagrados que cristãos e judeus compartilhamos, temos o livro dos Salmos, como oração comum. Vimos que a MV levantou salmos

${ }^{15}$ BONHOEFFER, D. Discipulado. pp. 203-204. 
que especialmente podem ser compreendidos como salmos de misericórdia. Eles mostram a solicitude de Deus que manifesta graça e ternura, perdoa, cura, resgata. Foram referidos na MV, por exemplo: o S1 103; o S1 146; o S1 147; e destacou-se a proclamação maior de que é eterna a misericórdia de Deus, conforme o Sl. 136. A confiança na misericórdia de Deus está expressa também no S1 51. Depois, como vimos acima, a MV fez referência aos profetas, particularmente Oseias, para mostrar que Deus quer a misericórdia mais que o sacrifício e para revelar que Deus mesmo se comove pelo amor e tem compaixão.

Esses textos resumem toda uma revelação de Deus e o seu chamamento para o povo de Deus viver de acordo com o Deus e sua justiça da salvação. Caberá aprofundar no diálogo tantos temas sobre como Deus fala e como escuta as aflições, que Deus parece escondido, mas que também mostrará sua fidelidade, que no seu amor, Deus se comove e perdoa, Deus restaura, Deus descortina um futuro novo. Deus fala ao coração. Deus ensina-nos a praticar a justiça e a misericórdia.

Percebe-se como a revelação da misericórdia divina e a exigência da misericórdia e as obras da misericórdia já estão no Antigo Testamento ou Primeiro Testamento. $\mathrm{O}$ tema se encontraria em outros escritos judaicos. Como ilustração do tema da misericórdia de Deus no perdão e na solicitude, eis um trecho de uma oração para o Yom Kippur:

Atende-nos, tu que perdoas e absolves, atende-nos.

Atende-nos, tu que estás presente nos dias de angústia, atende-nos.

Atende-nos, tu que resgatas e salvas, atende-nos.

Atende-nos, tu que és justo e reto, atende-nos.

Atende-nos, tu que estás perto daqueles que te imploram, atende-nos.

Atende-nos, tu que és bom e misericordioso, atende-nos.

Atende-nos, tu que escutas os desafortunados, atende-nos.

Atende-nos, tu que amparas os inocentes, atende-nos.

Atende-nos, pai dos órfãos, atende-nos.

Atende-nos, defensor das viúvas, atende-nos.

Louvado sejas, Senhor nosso Deus e Rei do universo, que nos abres os tesouros de tua generosidade e cuidas daqueles que esperam em tua misericórdia. Tu fazes a luz e crias a treva, tu fazes a paz e crias todas as coisas. Eterna fonte de luz e de vida, declaraste: desapareceu a escuridão e brilhou a luz. Neste dia solene, envia, de tua santa Morada, o perdão para a comunidade. ${ }^{16}$

${ }^{16}$ Cf. AVRIL, A-C; MAISONNEUVE, D. As festas judaicas. São Paulo: Paulus, 1997, pp. 131-132. 
A súplica dirige-se a Deus, pedindo-lhe perdão. A misericórdia de Deus é dada no perdão e em diversas formas de solicitude. Os cristãos podemos meditar o tema em comum com os Judeus. Podemos aprofundar o significado de uma oração voltada para a misericórdia de Deus. Podemos tomar a Deus como esperança de perdão e também como modelo para todos os que o invocam, colocando-se assim diante de Deus na confiança e na conversão.

\section{No diálogo com o Islamismo}

O Islamismo é uma importante tradição religiosa, que também tem uma forte referência à fé em Deus único e Misericordioso. Walter Kasper, no seu livro principal sobre a misericórdia, no capítulo em que reúne várias abordagens da misericórdia, situa o Islamismo falando da proximidade e da diversidade em relação aos cristãos, lembrando que tem diferenças, mas "tem raízes em determinadas tradições veterotestamentárias e neotestamentárias e é considerado com frequência, conjuntamente com o Judaísmo e o Cristianismo, entre as religiões abraâmicas monoteístas". ${ }^{17}$

O Papa Francisco explicita na MV que no Islamismo se invoca frequentemente a Deus como Misericordioso e Clemente. Quase todas as Suratas do Alcorão se iniciam com uma referência ao Nome de Deus, o Clemente, o Misericordioso. É conhecido também o texto dos 99 Nomes de Deus, dos quais os nomes Misericordioso e Clemente são os mais frequentemente citados. Eis como se inicia a oração muçulmana que invoca os 99 Nomes:

Ele é Deus,

Não há outro Deus além dele.

O Clemente, o Misericordioso,

o Rei, o Santo, a Paz,

o Crente, o Muito forte, o Soberbo,

o Criador,

o Renovador, o Organizador,

o Doador, o Dispensador, o Vitorioso. ${ }^{18}$

Conforme visto, o Papa Francisco, MV, ao referir-se à valência da misericórdia em outras religiões, considerou a fé muçulmana na misericórdia de

\footnotetext{
${ }^{17}$ KASPER, W. A misericórdia: condição fundamental do Evangelho e chave da vida cristã, p. 52. ${ }^{18}$ TEIXEIRA, F. BERKENBROCK, V. (Orgs.). Sede Deus: Orações do Judaísmo, Cristianismo e Islã. Petrópolis: Vozes, 2002, p. 292.
} 
Deus. Como temos acentuado, também os cristãos creem na misericórdia, da qual todos necessitamos, de modo que esse é um dado para diálogo. As palavras do Papa Francisco na MV ao referir-se ao Islamismo são as seguintes:

O Islamismo, por sua vez, coloca entre os nomes dados ao Criador o de Misericordioso e Clemente. Esta invocação aparece com frequência nos lábios dos fiéis muçulmanos, que se sentem acompanhados e sustentados pela misericórdia na sua fraqueza diária. Também eles acreditam que ninguém pode pôr limites à misericórdia divina, porque as suas portas estão sempre abertas (MV, n. 23).

Felix Korner realiza um estudo sobre a teologia da misericórdia dentro de um diálogo cristão-muçulmano. Ele destaca a referência frequente ao nome de Deus, o Clemente, o Misericordioso. Korner expõe dados da perspectiva cristã, perguntando o que os cristãos entendem quando falam da misericórdia. Ele conclui que se trata de um Deus com amor concreto, "um amor histórico, obsequioso, inclusivo, e por isso arriscado". ${ }^{19}$ Já no AT revela-se misericordioso e depois no NT com Jesus. Deus empenha-se na história da salvação. Deus comunica sua própria vida. Komer aponta como particularmente representativa a eleição de Mateus, em que o Senhor, olhando-o com misericórdia, escolheu-o.

Depois de falar da perspectiva cristã, Felix Korner considera a perspectiva islâmica, na qual o Alcorão denomina Deus o Clemente, o Misericordioso. Korner observa que essa segunda denominação enfatiza a primeira. Prolongando o estudo da doutrina islâmica sobre a misericórdia, Korner vê que a misericórdia divina é dada com os aspectos de "sua providência, boa guia, indulgência e exemplaridade". ${ }^{20}$ Acrescenta a observação de que Deus, sendo onisciente, perdoa. Uma indicação particular é a ideia de que Deus prescreveu para si mesmo a misericórdia, ou que tem inscrita em Si a misericórdia. Além desses aspectos sobre a misericórdia divina, Korner haveria que considerar que os seres humanos podem e devem ser misericordiosos. Um modo de relacionar a misericórdia humana com a misericórdia de Deus é que todo ser humano espera de Deus o perdão e também deve seguir o exemplo de Deus.

Korner cita outros testemunhos da tradição islâmica que acentuaram a

\footnotetext{
${ }^{19}$ KORNER, F. “Teología de la misericordia: Un diálogo cristiano-musulmán”. In: AUGUSTIN, G. (ed.). El evangelio de la misericordia. Maliaño: Sal Terrae, 2016, p. 102.

${ }^{20}$ KORNER, F. Teología de la misericordia, p. 106.
} 
perspectiva da misericórdia, inclusive considerando que o que é falho pode ser transformado, e que por graça do rei o que é desagradável pode tornar-se belo. Korner explica que isso levaria a ver que "até o mais prosaicamente humano se converte em uma obra mestra. Quem compreendeu isso nunca desejará ocultar a Deus seu lado obscuro. [...] Pois tudo o que Deus vê torna-se salutar, mais ainda, bom". ${ }^{21}$

Tendo em conta o seu estudo sobre a doutrina da misericórdia no Cristianismo e no Islamismo, Korner conclui que "quando dois interloctores se expõem um ao outro com sinceridade, é de esperar que elas sejam contempladas em ambos os casos com um olhar reconciliador, curativo e misericordioso". Desse modo, o diálogo faz-se no respeito, na sinceridade e na misericórdia.

\section{No diálogo com o Hinduísmo}

O que costumamos chamar de Hinduísmo corresponde a uma diversidade de correntes e a um mundo cultural e religioso que não possui um credo único nem uma instituição central. Vasudha Narayanan, ao apresentar uma introdução ao Hinduísmo, propõe a pergunta: "É o hinduísmo uma religião, uma cultura, ou, como diriam muitos hindus, um modo de vida?" A autora acrescenta que no Hinduísmo "aquilo que no Ocidente poderia ser considerado como fronteiras entre a esfera sagrada e a esfera profana não se aplica às tradições hindus". ${ }^{22}$ Várias atividades humanas aparecem como sagradas e no hinduísmo indicam-se vários caminhos contribuindo para a libertação do ciclo repetido de vida e da morte, que é uma das crenças hindus. Dentro de suas crenças e de suas atividades podemos encontrar o elemento da compaixão. Talvez o modo de compreender a compaixão seja um pouco diferente, mas podemos considerar que inspira uma atitude de respeito à vida e de boa ação.

Vasudha Narayanan mostra que haveria três caminhos de libertação, ou três dimensões de uma única disciplina: o caminho da ação; o do conhecimento; e o da devoção. Cada um tem contribuições interessantes. Podemos, por um momento, nos deter no primeiro desses aspectos: trata-se de realizar uma ação e ao mesmo tempo caminhar para a própria pacificação. A ação deve ser altruísta, para o bem da humanidade, caracterizada por um espírito de compaixão:

\footnotetext{
${ }^{21}$ KORNER, F. Teología de la misericordia, p. 106.

${ }^{22}$ NARAYANAN, V. Conhecendo o Hinduísmo. Petrópolis: Vozes, 2009, p. 9.
} 
O caminho da ação (Karma yoga) é o caminho da ação altruísta: a pessoa deve cumprir seu dever (dharma), como estudar ou praticar boas ações, mas não por temor de repreensão ou castigo, ou por esperança de elogio ou recompensa. Renunciando assim aos frutos de sua ação, a pessoa alcança uma paz permanente. Isso implica agir de forma altruísta para o bem da humanidade e executar todas as ações de maneira compassiva. ${ }^{23}$

O tema do altruísmo e principalmente o da compaixão merecem ser aproximados em um diálogo inter-religioso e universal sobre a misericórdia. Walter Kasper chama a atenção de que o termo análogo à "compaixão" ou "empatia" no Hinduísmo seria ahimsa, podendo ser interpretado de modos diversos. O termo "compaixão" (ou ahinsa) designaria "a renúncia a tudo o que é prejudicial e ao uso da violência". Nesse sentido e como regra de conduta, o termo estaria testemunhado a partir do final da época védica. ${ }^{24}$

Mahatma Gandhi renovou o antigo ideal de conduta acentuando esse aspecto de não-violência, que deve ser aplicado em todas as esferas da vida, inclusive a política. A postura de Gandhi e sua liderança pela não-violência são amplamente conhecidas. Movimentos posteriores marcados pelo hinduísmo conservam esses traços. Assim aconteceu no movimento dos Ashram e formas de meditação do Ioga. Embora nem sempre as transposições para o Ocidente tenham sido feitas adequadamente, o tema da não-violência permanece grande para o diálogo, não só no sentido de conhecermos e estimarmos os interlocutores, mas com vistas a integrar esse conceito em nossas relações humanas e com o universo.

É de todo importante que os tema da compaixão e da não-violência, que achamos presentes no Hinduísmo, sejam acolhidos para um diálogo amplo da misericórdia. Na diversidade de aspectos, podem por sua vez inspirar e enriquecer as nossas concepções e atitudes. Somam na compreensão do que é um caminho de vida verdadeiramente humano. Os valores de altruísmo e compaixão (também como renúncia ao prejudicial e a todo uso de violências) têm muito a dizer e apoiar quando desejamos e precisamos ser sensíveis às pessoas nos seus sofrimentos, bem como para promover todo o bem e a paz da humanidade.

$\mathrm{Na}$ sabedoria (religiosa) hindu, entre muitos outros dados e aspectos, existem orientações para a devoção, o conhecimento e o altruísmo. O Hinduísmo é muito mais do que está registrado em seus livros sagrados. Entretanto,

\footnotetext{
${ }^{23}$ NARAYANAN, V. Conhecendo o Hinduísmo. Petrópolis: Vozes, 2009, p. 52.

${ }^{24}$ KASPER, W. A misericórdia: condição fundamental do Evangelho e chave da vida cristã, p. 51.
} 
são inúmeros os poemas hindus. Chama a nossa atenção neste momento um hino védico que louva a Fé. Não é este o lugar para discutir o problema da conceituação de fé entre os hindus ou os cristãos. Pode-se, porém, talvez perceber uma implicação entre a fé e a obra de dar. Seria oportuno contemplar essa relação? Nosso tempo precisa de fé, bem como de disponibilidade para dar algo que se possui ou algo de si mesmo. E certamente de esperança, e de oração. Temos visto como a fé cristã está implicada com a misericórdia e podemos pensar que a misericórdia ajuda a viver com alguma forma de fé. A disponibilidade para dar, particularmente a obra caritativa, ajuda de algum modo a crer na humanidade e a crer na Divindade. Ou a crer e esperar - e também a atuar em prol da fé, das pessoas, de algo de bom que se pode preparar desde já. E ainda a crer e esperar algo melhor ainda por vir. Podemos pensar no gesto de doar, de um coração que é aberto e que contribui.

No hino védico a que aludíamos e que citaremos, um belo verso pede a bênção à Fé. Pede-lhe para abençoar o homem que dá ou que daria de bom brado. Talvez se tratasse uma oferenda para a Divindade, talvez no templo? O início do hino faz alusão a uma oferenda. Sempre caberia pensar em uma disposição de desapego, pronta e generosa. Em todo caso, existem outros textos védicos sobre a liberalidade, para dar a quem necessita, considerando que na roda da vida podemos em algum momento ter posses e em outro momento estar desprovidos e por nossa vez necessitar que alguém nos ajude. ${ }^{25}$ No poema em que se pede a bênção à Fé, haveria talvez uma alusão à disposição de ajudar? Seria o homem misericordioso que estaria a pedir a bênção da fé? Pediria recompensas? O pedido de bênção seria um ato da sua fé? Observa-se o pedido feito em favor de quem doa e igualmente em favor daquele que tem em si a disposição interior para doar, e que, portanto, realizaria a obra (de misericórdia) na medida da possibilidade. Na forma de um hino para a Fé, em seu louvor, não teria o texto talvez também a intenção de louvar o desapego ou a própria obra de misericórdia, de modo que o texto serviria para comover os corações?

De qualquer modo, o hino pode ser inspirador. A relação entre a fé e a obra de misericórdia é sempre sugestiva, pois uma pode favorecer a outra, e ambas são elementos a respeitar e valorizar no diálogo. $\mathrm{O}$ alcance do poema pode ficar em aberto. Que ele contribua com a sua beleza e os seus apelos. Fale-nos mais intuitivamente do que analiticamente. $\mathrm{O}$ hino em questão se intitula "A Fé" e o verso singelo ao qual nos referimos é o seguinte:

\footnotetext{
${ }^{25}$ Ver poema dos Rig-Veda sobre liberalidade e bondade em YUTANG, L. A sabedoria da india e da China. Vol. 1. Rio de Janeiro: Irmãos Pongetti, 1955, pp. 31-32.
} 
Abençoa o homem que dá, ó Fé;

Fé, abençoa o homem que daria de bom grado. ${ }^{26}$

\section{No diálogo com o Budismo}

O Budismo também não é um sistema único ou uniforme. O Budismo existe em várias formas. Tem aspectos de sabedoria e de religiosidade. Fala em iluminação e libertação. O itinerário espiritual de Sidarta Gautama foi marcado pela experiência de se deparar com o sofrimento e de verificar como a vida é sofrimento. Sua experiência fundamental de iluminação levou-o a um caminho ético e meditativo de superação, marcado pela bondade e a compaixão. Essa bondade e compaixão se aplicam a todos os seres. Trata-se de uma vivência do amor e da solicitude em amplitude universal. Consideramos que esses elementos vêm a ser muito importantes para um diálogo da misericórdia e da compaixão. Walter Kasper dá um resumo dessas características do Budismo:

A superação do mal por meio da conduta ética, do ensinamento meditativo e da compaixão converteu-se no propósito fundamental da doutrina da sapiência budista. No caminho até este objetivo, a bondade ( $\mathrm{metta}$ ) também tem um lugar. Trata-se de uma forma de amor ativa e desinteressada que persegue o bem-estar de todos os seres sensitivos. É expressão da compaixão (Karuna), isto é, da partilha, através da empatia, do sofrimento e do destino das pessoas e de todos os seres vivos. Por consequência, trata todos os seres e todas as manifestações deste mundo com a mesma amplitude de amor e solicitude. ${ }^{27}$

A doutrina e a meditação budista têm várias riquezas e formas de apresentação, mas que para um não iniciado ficam muitas vezes impenetráveis. Entretanto, procuraremos aqui aproximar alguns elementos que podem entrar em diálogo com a temática que estamos abordando. Para o Budismo, apresenta-se a meta da iluminação e libertação, que levaria a progredir para o estado de Buda. Porém, um ponto inspirador para o diálogo da misericórdia e da

\footnotetext{
${ }^{26}$ Cf. YUTANG, L. A sabedoria da índia e da China. Vol. 1, pp. 32-33. É um outro um hino védico. Esse hino, relativamente breve, repete várias vezes a palavra fé e elogia as pessoas liberais. Aproxima-se do tema de agir com compaixão ou com misericórdia. Um verso faz referência ao coração: o homem conseguiria a fé pelas "emoções do coração". De modo inverso, conseguiria também a riqueza pela fé.

${ }^{27}$ KASPER, W. A misericórdia: Condição fundamental do Evangelho e chave da vida cristã, pp. 51-52.
} 
compaixão pode ser o lugar que tem no Budismo o ideal do bodhisattva. No dizer de Gyamtso, do Centro de Estudos Budistas KPG, esse ideal seria ter "a mente voltada para a obtenção do Despertar pelo bem dos seres", com a vontade de ajudar todas as pessoas a sairem do sofrimento:

O bodhisattva é aquele que assume para si o objetivo mais amplo que possa existir e deseja se dedicar inteiramente ao meio mais poderoso que houver para alcançá-lo. Que objetivo é esse? Ajudar todos os seres a sair do sofrimento, seja temporariamente, por meio da busca de soluções para as dificuldades que encontram no ciclo das existências, ou de forma definitiva, ao conduzi-los pelo caminho da libertação. ${ }^{28}$

A citação acima é extraída de um comentário a um texto de Thokmé Zangpo, intitulado "As Trinta e Sete Práticas dos Filhos dos Vitoriosos". As últimas práticas propõem um resumo, para "realizar incessantemente o bem dos outros" e para isso "dedicar o Despertar às virtudes":

(36) Em resumo, o que quer que façamos, em qualquer área,

Devemos nos perguntar: "Qual é o estado de nossa própria mente?"

Incessantemente, realizar o bem dos outros,

Atenção e memória, é a prática dos Filhos dos Vitoriosos.

(37) Para dissipar o sofrimento de incontáveis seres,

Por meio de uma sabedoria totalmente livre das três esferas,

Dedicar ao Despertar as virtudes do esforço realizado conforme explicado

É a prática dos Filhos dos Vitoriosos. ${ }^{29}$

É interessante esclarecimento do Lama Jigme Rimpoche em diálogo com o monge beneditino Dom RobertLe Gall. O lama budista esclarece que "um bodhisattva é um ser que fez os votos de ajudar todos os seres. Quando atinge o Despertar, ele não permanece, simplesmente, na paz do nirvana, mas consagra-se ao bem do outro". ${ }^{30} \mathrm{O}$ seu trajeto espiritual deve ser sempre marcado por amor e compaixão:

${ }^{28}$ GYAMTSO, K. P. "Comentário ao texto As Trinta e Sete Práticas dos Filhos dos Vitoriosos". In: GONÇALVES, R.M.; MONTEIRO, J.; REDYSON, D. (Org). Antologia Budista. São Paulo: Fonte Editorial, p. 299.

${ }^{29}$ ZANGPO, T. “As trinta e sete práticas dos filhos dos vitoriosos”. In: GONÇALVES, R. M.; MONTEIRO, J.; REDYSON, D. (Orgs). Antologia Budista. São Paulo: Fonte Editorial, 2015, p. 297.

${ }^{30}$ LE GALL, R; RINPOCHE, J. O Monge e o Lama. Diálogo entre Budismo e Cristianismo. Rio de Janeiro: Bertrand Brasil, 2003, p. 65. 
O trajeto espiritual, fundamentado na renúncia e na perseverança, leva a um certo estado de liberação, mas não ao pleno Despertar, que é o estado de perfeição de Buda. A esse desemvolvimento falta o desabrochar pleno da dimensão do amor e da compaixão que se estende a todos os seres sensíveis, sem o qual não se chega à perfeita realização. [...] Amor, na língua tibetana, é djampa, e compaixão, nyindje. Djampa designa o sentimento de interesse equânime e profundo pela sorte de todos os seres. Todos os seres têm importância para nós e sentimos, em relação a eles, uma intensa solicitude. Desejamos, do fundo do coração, poder estabilizá-los num estado de felicidade. O amor é isso. A compaixão é o que sentimos quando percebemos que alguém é submetido, ou corre o risco de se submeter algum dia, a condições bem difíceis, dolorosas: desejamos proteger essa pessoa, queremos intervir de uma maneira ou de outra. A compaixão vem da clara compreensão que temos do sofrimento das pessoas, quer ele seja presente, passado ou um sofrimento a vir. A compaixão é um sentimento profundo que nos leva a agir para livrar as pessoas do sofrimento. ${ }^{31}$

Desse modo, de acordo com o ensinamento desse budista tibetano, pelo amor temos interesse e solicitude por todos os seres. Pela compaixão, temos compreensão por elas em seu sofrimento e agiríamos para livrá-las do sofrimento. O diálogo da misericórdia pode enriquecer-se com bondade / amor e compaixão. Seriam traços de humanidade, perfeição e caminho da libertação.

É sabido que o Dalai Lama dedica-se não somente aos ensinamentos budistas, mas também ao diálogo inter-religioso. Ele ensina o respeito pelas diferentes convicções e tradições religiosas e faz ver as pontes entre as religiões. Ele coloca-se na linha de uma comunhão no essencial. Para ele, os principais dados de uma "ética religiosa básica" comum seriam a bondade amorosa e a compaixão:

Todas as religiões do mundo ensinam, no plano da motivação - ou seja, do estado de espírito - o cultivo da bondade amorosa e da compaixão, enquanto, no plano da ação cotidiana, ensinam a ética de evitar ações prejudiciais. Assim, seja no contexto do coração ou das ações no mundo e em relação aos outros seres, o ensinamento básico é, em essência, a compaixão. ${ }^{32}$

${ }^{31}$ LE GALL, R; RINPOCHE, J. O Monge e o Lama, pp. 62-63.

${ }^{32}$ DALAI LAMA. Uma ponte entre as religiões. Por uma verdadeira comunhão da fé. São 
Assim como a regra de ouro, compartilhada em todas as grandes tradições religiosas e que constitui um ditame da consciência, também "bondade amorosa e compaixão" são elementos humanos fundamentais e ao mesmo tempo religiosos. Uma coisa implica na outra. É significativo compartilhar esses valores. Com eles buscamos uma comunhão no essencial e movemo-nos, mesmo que a partir de perspectivas diversas, para uma fraternidade universal, dedicada ao bem e à libertação de todos.

\section{Considerações finais}

O Jubileu Extraordinário da Misericórdia incentiva-nos a nos empenharmos em tornar nossos tempos como tempos de misericórdia, a partir do dom do amor misericordioso de Deus. O evento do ano se encerra, mas não o que ele propõe. Deus é rico em misericórdia e os cristãos devem ser testemunhas e sinais do dom da misericórdia. O Jubileu faz contemplar o mistério da misericórdia e a ter presente que ela "é fonte de alegria, serenidade e paz" e "condição de nossa salvação" (MV, n. 2).

$\mathrm{Na} \mathrm{MV}$ encontramos linhas de reflexão a partir do Antigo e do Novo Testamento, e riquezas teológicas e espirituais da tradição da Igreja, junto com a orientação para sermos em nosso tempo "misericordiosos como o Pai". Para os cristãos, o tema da misericórdia é central na sua fé em Deus e na práxis do seguimento de Cristo, pois a misericórdia é dom do Amor de Deus que se revela e no qual devemos viver - na fé, na oração e na ação.

Muitos dados da riqueza espiritual dos cristãos têm raízes judaicas. Um dos caminhos do diálogo com os Judeus deve ser rememorar a fé na misericórdia e no perdão de Deus, que nos leva à oração confiante e a ter em conta Seus ensinamentos, inclusive como modelo para nossas obras de misericórdia e nossas relações humanas.

O Papa Francisco incentiva os fiéis a um diálogo amplo, da misericórdia, no encontro com as tradições religiosas. Encontramos nas tradições religiosas elementos para o aprofundamento de valores espirituais e humanos. Nos contextos religiosos com a recomendação da regra de ouro, da solidariedade e do auxílio aos outros, da busca de superação dos sofrimentos, do respeito para com todos os seres, esses elementos bem poderiam contribuir para o diálogo e a prática da misericórdia.

Paulo: Martins Fontes, 2014, p. 141. 
Na verdade, esse seria um diálogo aberto a todas as pessoas e profissões. Deveria ser desenvolvido na interdisciplinaridade. Achamos que seria um diálogo de escuta, palavra, estudos, valores e atitudes, aplicando-se a tudo o que humaniza e que contribui para a inclusão, o cuidado das pessoas e a libertação dos sofrimentos. E, do mesmo modo, para o perdão, a reconciliação, a paz.

O diálogo da misericórdia fica enriquecido com todas as contribuições de misericórdia, compaixão, empatia, não-violência, renúncia ao mal, promoção da justiça, atendimento, solidariedade, bondade, humanidade... Está em ir ao encontro, acolher, escutar, falar, reconhecer, promover, contribuir, doar-se, relacionar-se - nos valores que mencionamos e com essas atitudes e ações. Está em abrir o coração, em colocar o coração junto ao outro. Seja sobre sua fonte e modelo em Deus, seja sobre as exigências práticas para todos nós, ou ainda sobre as modalidades de sua realização, o diálogo da misericórdia e da compaixão merece ser sempre aprofundado.

\section{Referências bibliográficas}

AGOSTINI, L. Eterna é a sua misericórdia: Reflexões bíblicas e Leituras orantes. São Paulo: Paulinas, 2016.

AVRIL, A-C; MAISONNEUVE, D. As festas judaicas. São Paulo: Paulus, 1997.

BONHOEFFER, D. Discipulado. São Leopoldo: Sinodal, 2004.

CONCÍLIO VATICANO II. "Decreto Unitatis Redintegratio, sobre o ecumenismo". In: COMPÊNDIO DO VATICANO II. Constituição Decretos. Declarações. 21 ed. Petrôpolis: Vozes, 1991, pp. 307-332.

DALAI LAMA. Uma ponte entre as religiões. Por uma verdadeira comunhão da fé. São Paulo: Martins Fontes, 2014.

FEBVRE, L. Martinho Lutero, um destino. São Paulo: Três Estrelas, 2012.

FRANCISCO, PP. Misericordiae Vultus. Bula de proclamação do Jubileu Extraordinário da Misericórdia. São Paulo: Paulinas, 2015.

GYAMTSO, K. P. "Comentário ao texto As Trinta e Sete Práticas dos Filhos dos Vitoriosos”. In: GONÇALVES, R.M.; MONTEIRO, J.; REDYSON, D. (Orgs.). Antologia Budista. São Paulo: Fonte Editorial, 2015, pp. 299-303.

KASPER, W. A misericórdia: condição fundamental do Evangelho e chave da vida cristã. São Paulo: Loyola, 2015. 
KASPER, W. El desafio de la Misericordia. Maliaño: Sal Terrae, 2015.

KASPER, W. Martín Lutero - Una perspectiva ecuménica. Maliaño: Sal Terrae, 2016.

KORNER, F. "Teología de la misericordia: Un diálogo cristiano-musulmán". In: AUGUSTIN, G. (Ed.). El evangelio de la misericordia. Maliaño: Sal Terrae, 2016, pp. 101-114.

LE GALL, R; RINPOCHE, J. O Monge e o Lama. Diálogo entre Budismo e Cristianismo. Rio de Janeiro: Bertrand Brasil, 2003.

NARAYANAN, V. Conhecendo o Hinduísmo. Petrópolis: Vozes, 2009.

PAULO VI. Encíclica Ecclesiam Suam. In: Documentos de Paulo VI. São Paulo: Paulus, 1997.

SÁNCHEZ MONGE, M. Este es el tiempo de la misericordia. Maliaño: Sal Terrae, 2016.

TEIXEIRA, F. BERKENBROCK, V. (Orgs.). Sede Deus: Orações do Judaísmo, Cristianismo e Islã. Petrópolis: Vozes, 2002.

YUTANG, L. A sabedoria da Índia e da China. Vol. 1. Rio de Janeiro: Irmãos Pongetti, 1955.

ZANGPO, T. "As trinta e sete práticas dos filhos dos vitoriosos". In: GONÇALVES, R. M.; MONTEIRO, J.; REDYSON, D. (Orgs). Antologia Budista. São Paulo: Fonte Editorial, 2015, pp. 291-298.

\section{Maria Teresa de Freitas Cardoso}

Doutora em Teologia pela Pontifícia Universidade Católica do Rio de Janeiro Professora de Teologia na PUC-Rio Rio de Janeiro - RJ / Brasil E-mail:mtfcardoso@puc-rio.br

Recebido em: 23/08/16

Aprovado em: 11/09/16 